\title{
INFLUENCE OF AIR-JET EROSION ON THE DETONATION-GUN SPRAYED ALUMINA-ZIRCONIA CERAMIC COMPOSITE COATINGS
}

\author{
Raja Kumar S. ${ }^{1}$, Vijayaraghavan L. ${ }^{2}$, Mayuram M.M. ${ }^{3}$ \\ ${ }^{1}$ Research Scholar, Department of Mechanical Engineering , Indian Institute of Technology Madras, Chennai, India. \\ ${ }^{2,3}$ Department of Mechanical Engineering, Indian Institute of Technology Madras, Chennai, India. \\ Email: ${ }^{1}$ me06d007@smail.iitm.ac.in
}

\begin{abstract}
Erosion due to solid particles impact has a detrimental effect on the performance of components used in various applications. Hard facing is widely used to combat wear in such situations. D-gun coating is increasingly popular for such applications. Aluminazirconia composite has been deposited on mild steel substrate. The coating has been characterized and their tribological responses have been evaluated. Resistance to erosion, evaluated through standard dry erosion test is highlighted in this work. An orthogonal full-factorial experimental matrix which includes all possible variables that contribute to brittle erosion was designed, conducted and validated. The variation of erosion rate with process parameters was mathematically modeled by using the regression analysis method.
\end{abstract}

Keywords: Detonation gun, Alumina-Zirconia, Erosion rate, Air-jet Erosion.

\section{INTRODUCTION}

In abrasion the metal component is gradually worn away by the repeated scratching or sourcing action of small abrasive particles such as sand, dust or soil moving across the metal surface at varying velocities. The abrasive particle is often not fractured, but it does scratch out small slivers of metals. This type of wear is also called two-body abrasion. Since only the abrasive and the metal body are involved low stress wear is the predominant type of abrasion that take place in both low velocity systems like earth moving, agriculture, classifier, screens and augers as well as high velocity systems like slurry pump, nozzles, cyclones and sand slinger.

Hard facing particularly surfacing through thermal spraying is widely used to combat wear in such situations. $\mathrm{D}$-gun coating, one of the thermal spraying processes, is increasingly popular owing to its versatility in spraying a large number of materials and is new to Indian scenario. Due to its dense structure, finer finish and higher bonding characteristics detonation coatings are apt for more critical applications in contrast the reported defects and need for post treatment in the case of plasma spayed depositions.

\section{COATING MATERIAL}

The fused alumina-zirconia ceramics composite is grayish blue in color and having the composition of $\mathrm{Al}_{2} \mathrm{O}_{3}$ $75 \%, \mathrm{ZrO}_{2} 23 \%$ and the remaining are $\mathrm{CaO}, \mathrm{SiO}_{2}, \mathrm{Na}_{2} \mathrm{O}$, and $\mathrm{Fe}_{2} \mathrm{O}_{3} \mathrm{TiO}_{2} \mathrm{HfO}_{2}$ [1]. The fused alumina zirconia powder is a blocky shaped with grayish blue in color. It produces a coating that is dense and hard and it resists wear due to abrasion, fretting, cavitations and particle erosion. The AZ powder size is 150 to $200 \mu \mathrm{m}$, which is not suitable for detonation spraying processes. So the powder size is reduced by ball milling using ceramic balls of 80 Nos with $\varnothing 25 \mathrm{~mm}$ and 40 Nos of $\varnothing 10 \mathrm{~mm}$ balls in a ceramic container. The container is $\varnothing 150 \mathrm{~mm}$ and $300 \mathrm{~mm}$ length. It runs for 3hours at 80rpm for crushing 20gms of AZ powder to $25 \mu \mathrm{m}$.
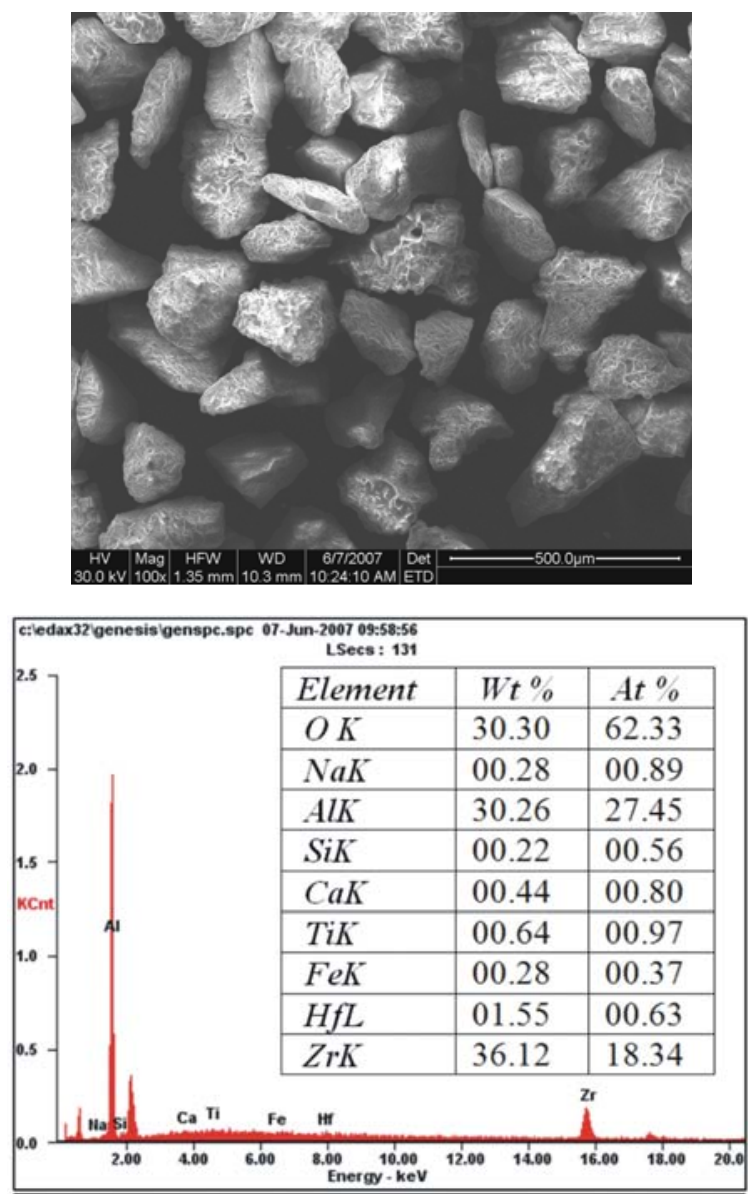

Fig 1. SEM micrograph \& EDAX quantification standard table showing AZ powder before crush. 
Fig 1\&2 SEM microscope of alumina zirconia powder before crush and crushed powder and EDAX quantification with standard table are shown, the elements are tabulated with percentage weight and percentage atomic. The SEM microscope shows that there is a reduction in powder size with the same element content. Fig.3. Shows the size distributions of the crushed powder measured using Microtac SRA 150 Model particle size instrument. This instrument measures particle size based on forward light scattering and diffraction. It is seen that $A Z$ powder ranges between $2.22 \mu \mathrm{m}$ and $69.03 \mu \mathrm{m}$ with a peak volume fraction at about $22.43 \mu \mathrm{m}$. Also shown in Fig 4 is the cumulative volume fraction as a function of particle size. Table 1 gives the particle size and its percentile details.
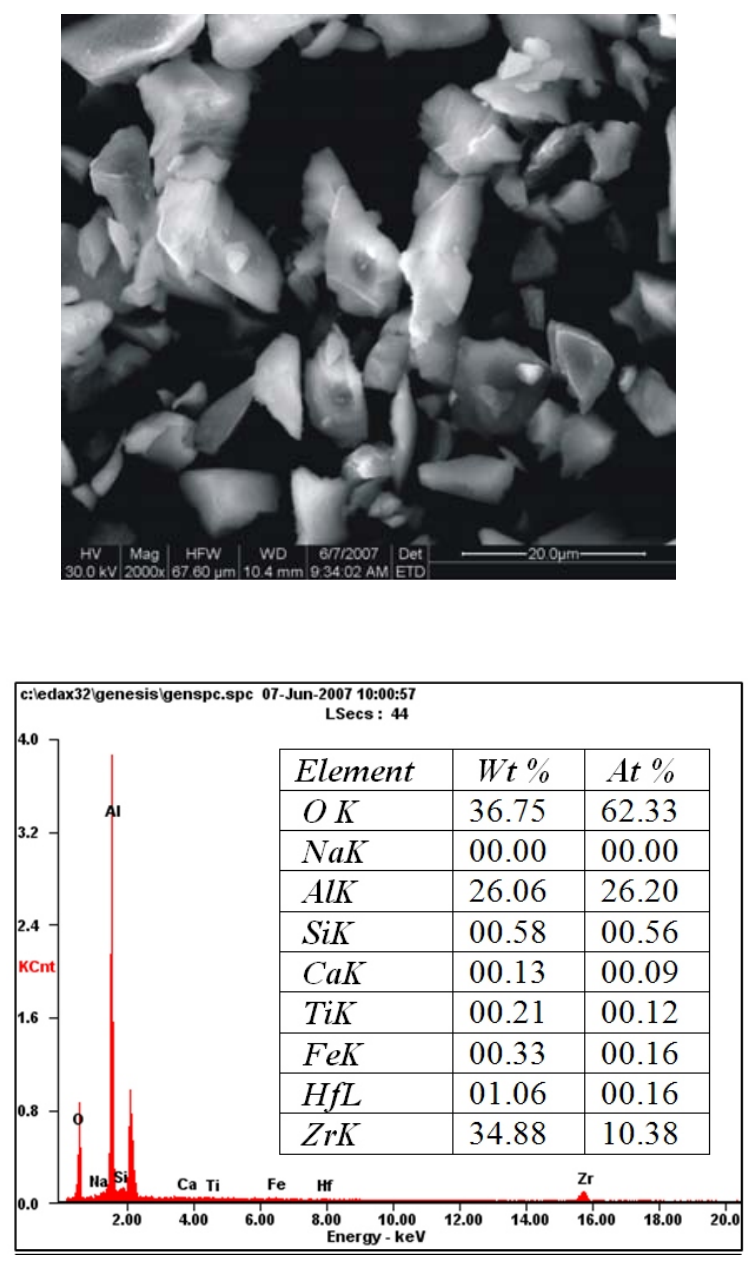

Fig. 2. SEM micrograph \& EDAX quantification standard table showing AZ crushed powder
Table 1. Particle size distribution details

\begin{tabular}{|c|c|c|}
\hline \hline Sl.No & $\begin{array}{c}\text { Percentile } \\
(\mathbf{\%})\end{array}$ & $\begin{array}{c}\text { Size } \\
(\mathbf{\mu m})\end{array}$ \\
\hline 1 & 10 & 2.222 \\
\hline 2 & 20 & 4.37 \\
\hline 3 & 30 & 7.66 \\
\hline 4 & 40 & 12.07 \\
\hline 5 & 50 & 16.76 \\
\hline 6 & 60 & 21.32 \\
\hline 7 & 70 & 26.45 \\
\hline 8 & 80 & 33.25 \\
\hline 9 & 90 & 47.09 \\
\hline 10 & 95 & 69.03 \\
\hline
\end{tabular}

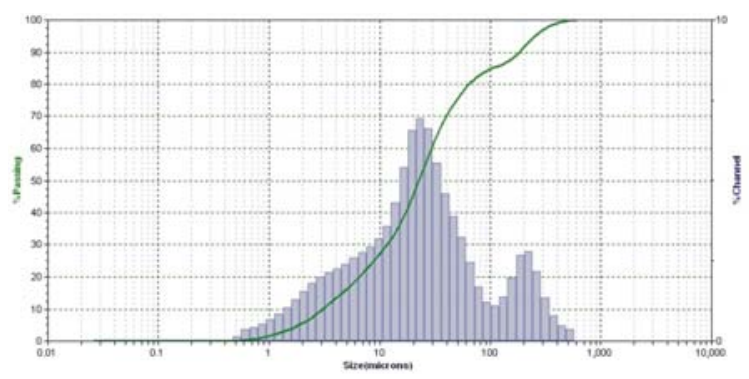

Fig. 3. Particle size distribution of fused Alumina Zirconia powder after crushed

D-Gun produces a coating that is dense and hard and it resists wear due to abrasion, fretting, cavitation and particle erosion. Typical erosion models emphasize that erosion rate is a function of target material properties like hardness, fracture toughness and target material density. When striking particles are assumed as non-deforming, the applicability of the model [2] is limited to soft targets. For gas/particle high concentration erosion, Models [3] is proposed wherein the authors have included target density as an additional parameter. In the models [4], erosion rate of alumina ceramic is related to velocity and size of silicon carbide particles at normal-incidence. The authors predicted that erosion rate increases with increasing velocity and angle of impact.

\section{III.DETONATION GUN SYSTEM}

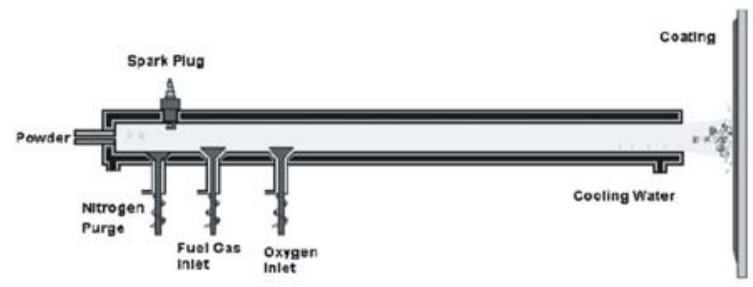

Fig. 4. Schematic of a Detonation gun 
The D-gun coating system, shown in Fig 4, consists of $25.4 \mathrm{~mm}$ inner diameter, $2.25 \mathrm{~m}$ long stainless steel detonation tube positioned at one end, near to a substrate holder and at the other end has a detonation venting section. The substrates in the form of $25 \times 25 \mathrm{~mm}$ square piece with $6 \mathrm{~mm}$ thickness mild steel samples were held in vice. The fused alumina-zirconia powder were propelled along the detonation tube placed at the specified distance i.e., stand off distance from the substrate location. The detonation wave was initiated by igniting the acetyleneoxygen i.e., fuel oxygen gas mixture at the closed end of the tube by an electric spark. The powder particles were entrained into the convection flow behind the passing detonation wave. The entrained particles experienced the thermodynamic conditions behind the wave for a certain residence time, by the carrier flow gas and splashes on the substrate [5]. The advantage that a detonation wave provides is the uniformity of the thermodynamic and flow conditions created behind the wave that the particles are exposed to, which provides a unique advantage over other processes [6].

The input process parameters for D-Gun coating fused Alumina Zirconia powder by detonation process are: stand off distance $190 \mathrm{~mm}$, Carrier gas flow rate 2000Slph, Detonation frequency 3 Shots/s, Fuel (C2H2) of 1900Slph (Spray liters per hour) and oxygen of 4800Slph [7].The scanning electron micrograph Fig.5 showing the deposition with the surface presenting discrete splat formation and denser deposition with more inter splat coherency.

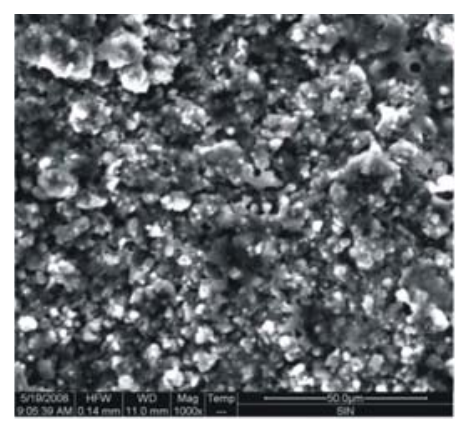

Fig. 5. SEM photograph of Alumina-Zirconia coating

\section{EXPERIMENTAL DETAILS}

\section{A. Air JetErosion Test}

Air-jet erosion test rig as per ASTM G65 was used to carry out air borne erosion tests. The erodent particles were entrained in a stream of compressed air and accelerated down a $65 \mathrm{~mm}$ long nozzle with $5 \mathrm{~mm}$ internal diameter to impact on a target mounted on an angle fixture $(300,450$ and 900$)$ as shown in Fig. 6 The particle velocity can be measured using the rotating double disk technique
[8] and it can be adjusted to desired values by varying the compressed air pressure. Air borne erosion tests were carried out on the coated samples under each condition. The dimensions of the specimen were $25 \mathrm{~mm} \times 25 \mathrm{mmX} 6$ $\mathrm{mm}$. The target samples were polished in order to have a smooth surface finish. The initial weight of the target was taken using an analytical balance of $\pm 0.1 \mathrm{mg}$ accuracy. The centre of the target specimens were maintained at $10 \mathrm{~mm}$ from nozzle orifice for all impingement angles. Each sample was eroded at velocities of 30,40 and $50 \mathrm{~m} / \mathrm{s}$ and the grit size of $120 \mu \mathrm{m}, 180 \mu \mathrm{m}$ and $230 \mu \mathrm{m}$. The test duration was $1 \mathrm{~min}$. At the end of each test, the target sample was taken out, cleaned, in air jet dried and weighed to calculate mass loss. This mass loss is taken to represent erosion loss.

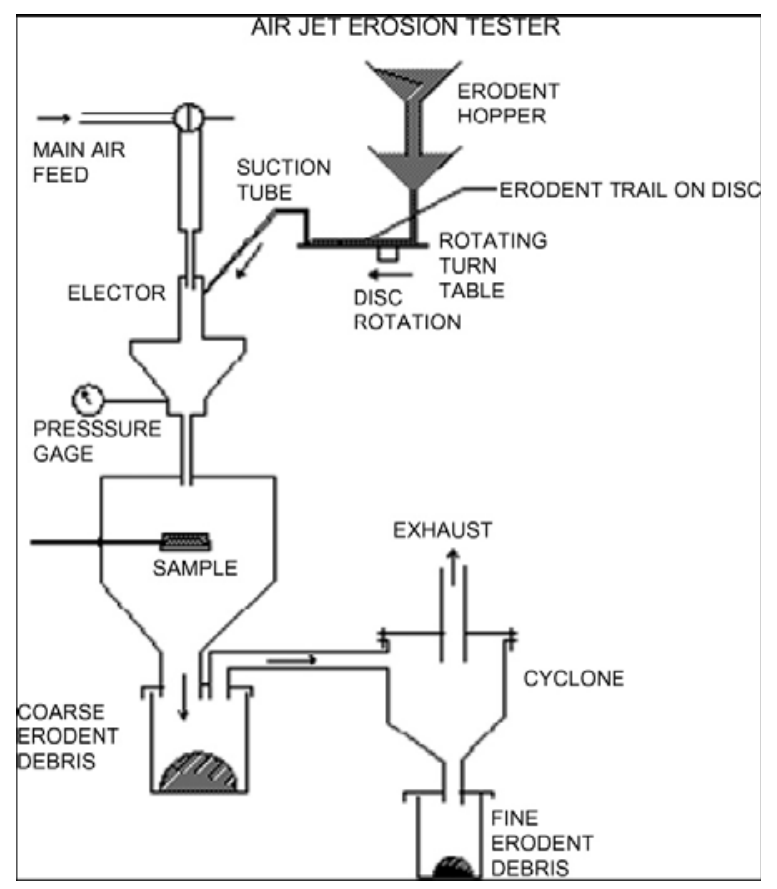

Fig. 6. Air-jet erosion test rig

\section{DESIGN OF EXPERIMENTS}

A three factor, three level full-factorial method was adopted to evaluate the influence of three major factors influencing erosion namely the velocity of impact, the angle of impact and the grit size of the erodent. By levels we mean the values taken by the factors. The orthogonal array chosen was $L_{27}\left(3^{3}\right)$ which have 27 rows corresponding to the number of tests (26 degree of freedom) with 13 columns. The factors and their interactions are assigned as per standard practice [9]. The statistical treatment of the data was made and then a mathematical model was developed between the given variables using multiple regression analysis. Finally, the 
experimental results were compared with the predicted values using confirmation test. The design for the $L_{27}$ fullfactorial was developed and analyzed using "MINITAB-14" software [10]. Table.2 gives the randomized order and conditions of the $\mathrm{L}_{27}$, which was used in the present study.

Table 2. Assigned full factorial $L_{27}\left(3^{3}\right)$ with the acquired data

\begin{tabular}{|c|c|c|c|c|c|}
\hline \hline $\begin{array}{c}\text { Std } \\
\text { Order }\end{array}$ & $\begin{array}{c}\text { Run } \\
\text { Order }\end{array}$ & $\begin{array}{c}\text { Grit } \\
\text { Size } \\
(\mu \mathrm{m})\end{array}$ & $\begin{array}{c}\text { Angle } \\
\text { of } \\
\text { impact } \\
(\theta)\end{array}$ & $\begin{array}{c}\text { Velocity } \\
(\mathrm{m} / \mathrm{s})\end{array}$ & $\begin{array}{c}\text { Erosion } \\
\text { rate } \\
(\text { grams })\end{array}$ \\
\hline 24 & 1 & 230 & 45 & 50 & 0.0002 \\
\hline 25 & 2 & 230 & 90 & 30 & 0.0078 \\
\hline 23 & 3 & 230 & 45 & 40 & 0.0213 \\
\hline 6 & 4 & 120 & 45 & 50 & 0.0008 \\
\hline 22 & 5 & 230 & 45 & 30 & 0.0012 \\
\hline 4 & 6 & 120 & 45 & 30 & 0.0217 \\
\hline 17 & 7 & 180 & 90 & 40 & 0.0043 \\
\hline 7 & 8 & 120 & 90 & 30 & 0.0030 \\
\hline 12 & 9 & 180 & 30 & 50 & 0.0052 \\
\hline 2 & 10 & 120 & 30 & 40 & 0.0007 \\
\hline 15 & 11 & 180 & 45 & 50 & 0.0101 \\
\hline 27 & 12 & 230 & 90 & 50 & 0.0006 \\
\hline 21 & 13 & 230 & 30 & 50 & 0.0022 \\
\hline 26 & 14 & 230 & 90 & 40 & 0.0092 \\
\hline 16 & 15 & 180 & 90 & 30 & 0.0109 \\
\hline 8 & 16 & 120 & 90 & 40 & 0.0102 \\
\hline 19 & 17 & 230 & 30 & 30 & 0.0003 \\
\hline 9 & 18 & 120 & 90 & 50 & 0.0034 \\
\hline 11 & 19 & 180 & 30 & 40 & 0.0086 \\
\hline 5 & 20 & 120 & 45 & 40 & 0.0076 \\
\hline 13 & 21 & 180 & 45 & 30 & 0.0074 \\
\hline 14 & 22 & 180 & 45 & 40 & 0.0005 \\
\hline 18 & 23 & 180 & 90 & 50 & 0.0040 \\
\hline 1 & 24 & 120 & 30 & 30 & 0.0072 \\
\hline 20 & 25 & 230 & 30 & 40 & 0.0018 \\
\hline 10 & 26 & 180 & 30 & 30 & 0.0011 \\
\hline 3 & 27 & 120 & 30 & 50 & 0.0010 \\
\hline
\end{tabular}

\section{EXPERIMENTAL RESULTS AND DATA ANALYSIS}

Fig. 7 depicts the plot of factor effects on erosion rate. Note that the data mean is used to determine each factor's effect. This figures serves the purpose of graphical assessment. The effect of velocity on erosion rate indicates that velocity has the most significant effect on erosion. In addition, erosion rate is directly proportional to the velocity; that is, with increasing velocity, the erosion rate increases significantly. The effect of angle of impact has a lesser impact compared to the velocity the impact. The grain size has a reversed trend compared to velocity, as the grit size increases the erosion rate is significantly reduced as mass reduces.

The factors effects are defined as the difference between the two extreme values of the response obtained for the corresponding factor. The interaction matrix is shown in Fig.8. It is used to visualize the interaction effect of the two factors on the response and to compare the relative strength of the effects. In the interaction matrix, the lines are nearly parallel to each other, i.e., there is not much interaction present, the change in the response mean from low to the high level of a factor does not depend on the level of a factor. The normal probability plot of residuals for erosion rate, Anderson-Darling (AD) statistic is displayed in Fig 9. Anormal probability plot is just a graph of the cumulative distribution of the residuals on normal probability paper, this graph paper with the ordinate scaled so that the cumulative normal distribution is plotted as a straight line [11]. If the P-value is higher than a-level of confidence (0.05), then the error normally is considered to be valid. The plot of residuals verses fitted value for erosion rate is shown in Fig. 10. It is evident that data points are structurelessly distributed. This indicates that variance constancy and error independency are valid.

The same conclusion as the graphical assessment can be drawn from ANNOVA analysis. Table 3 presents the analysis of variance (ANOVA) of the data with the erosion rate the analysis was carried out with the level of significance at $5 \%$, it means for a level of confidence of $95 \%$. From the analysis presented in Table 3 , it is observed that the velocity $(P=0.000)$ and grit size $(P=0.000)$ have statistical and physical significance on the erosion rate. The angle of impact $(P=0.050)$ is not as much significant as the two other two factors. Velocity with grit size level also have significance interaction effect $(P=0.000)$ while velocity with angle of impact $(P=0.191)$ and angle of impact with grit size $(P=0.225)$ have least significant interaction.

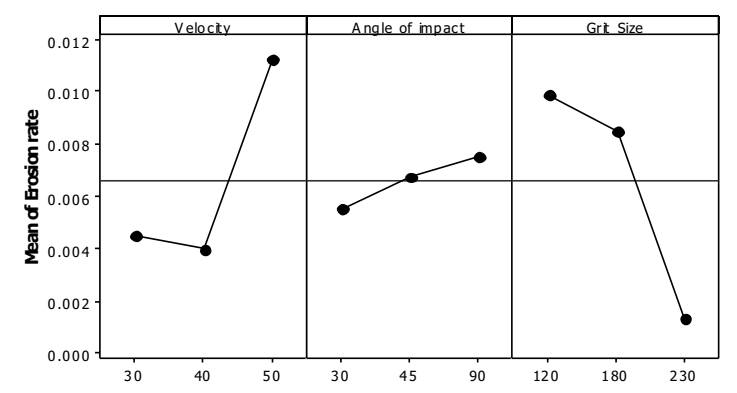

Fig. 7. Main effects plots of dry erosion rate

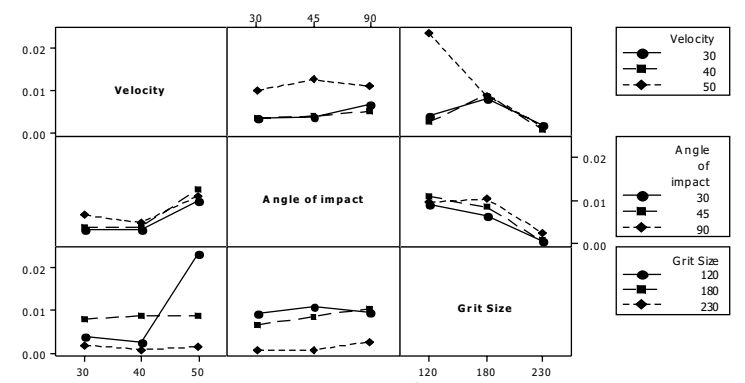

Fig. 8. Interaction plots of dry erosion rate 
Table 3. ANOVA Table

\begin{tabular}{|c|l|c|c|c|c|l|l|}
\hline SI.No & Source & DF & Seq SS & Adj SS & Adj SS & F & P \\
\hline 1 & Velocity & 2 & 0.0002949 & 0.0002949 & 0.0001475 & 71.42 & 0.000 \\
\hline 2 & Angle of impact & 2 & 0.0000185 & 0.0000185 & 0.0000092 & 4.47 & 0.050 \\
\hline 3 & Grit Size & 2 & 0.0003799 & 0.0003799 & 0.0001899 & 92.00 & 0.000 \\
\hline 4 & Velocity $^{*}$ Angle of Impact & 4 & 0.0000163 & 0.0000163 & 0.0000041 & 1.97 & 0.191 \\
\hline 5 & ${\text { Velocity }{ }^{*} \text { Grit Size }}$ & 4 & 0.0005406 & 0.0005406 & 0.0001351 & 65.46 & 0.000 \\
\hline 6 & Angle of impact ${ }^{*}$ Grit Size & 4 & 0.0000148 & 0.0000148 & 0.0000037 & 1.79 & 0.225 \\
\hline 7 & Error & 8 & 0.0000165 & 0.0000165 & 0.0000021 & & \\
\hline 8 & Total & 26 & 0.0012814 & & & & \\
\hline
\end{tabular}

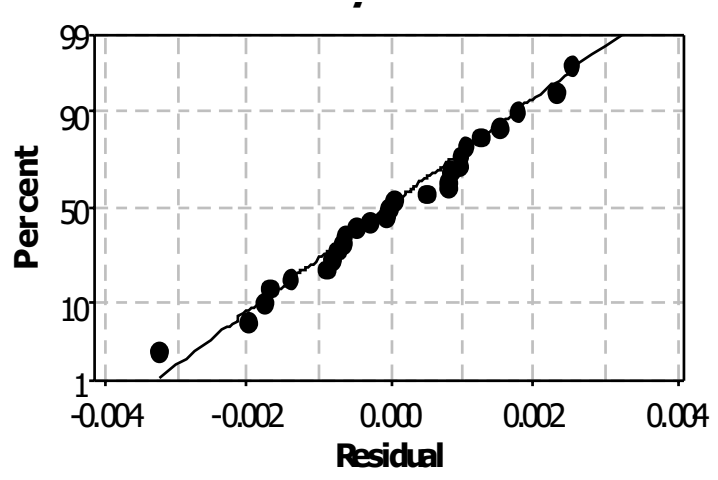

Fig. 9. Normal probability plots of residuals plot for erosion rate (grams)

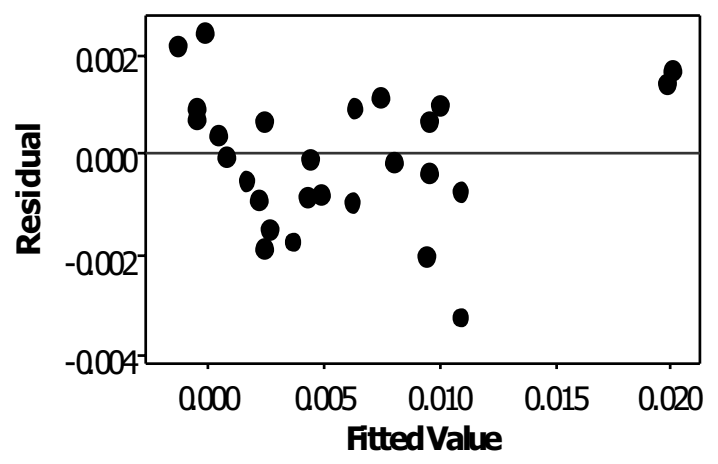

Fig. 10. Residual verses fitted values plot for erosion rate (grams)

\section{PROPOSED EROSION MODELS}

Two erosion models are formulated by reviewing the most-cited models in published literature. Model 1 for low concentration and Model 2 for high concentration applications. Most accepted models for dry-impact erosion do not include the trigonometric terms, however in the present model they have been added since its effect in case of alumina ceramic tiles was found to be a significant factor [12].

\section{Gas/particle "low" concentration}

$E \propto V^{A} D^{B} \rho_{\rho}^{C} K_{c}^{D} H^{E} \sin ^{F} \alpha$

\section{Gas/particle "high" concentration}

$E \propto V^{A} D^{B} \rho_{p}^{C} \rho_{t} K_{c}^{D} H^{E} \sin ^{F} \alpha$

\section{Nomenclature}

$$
\begin{array}{ll}
\text { D } & \text { diameter of particle }\left(\mathrm{g} / \mathrm{cm}^{3}\right) \\
E & \text { erosion rate }(\mathrm{g}) \\
H & \text { hardness of target }\left(\mathrm{kg} / \mathrm{mm}^{2}\right) \\
\mathrm{KC} & \text { fracture toughness of target }(\mathrm{MPa} \sqrt{\mathrm{m}}) \\
V & \text { air jet velocity }(\mathrm{m} / \mathrm{s}) \\
\alpha & \text { angle of impingement of particles }(\circ) \\
\rho_{p} & \text { density of particle }\left(\mathrm{g} / \mathrm{cm}^{3}\right) \\
\rho_{t} & \text { density of target }\left(\mathrm{g} / \mathrm{cm}^{3}\right)
\end{array}
$$

\section{REGRESSION ANALYSIS}

Based on dry-erosion test conducted, the following parametric-dependences have been determined, and compared with models from literature (Table 4) [13]. ANOVA is performed based on the estimates of the regression analysis and is presented in Table 4. The low Pvalue in Table 5 confirms the validity of the model within the permissible variation. 
Table 4. Polynomial values of literature and experimental Predictions

\begin{tabular}{|l|l|l|}
\hline $\begin{array}{l}\text { Exponent/ } \\
\text { Polynomial }\end{array}$ & $\begin{array}{l}\text { Literature } \\
\text { model }\end{array}$ & $\begin{array}{l}\text { Experimental } \\
\text { Predictions }\end{array}$ \\
\hline A & +2.80 & +2.65 \\
\hline B & +0.66 & +0.46 \\
\hline C & +1.30 & +1.56 \\
\hline D & -1.33 & -1.18 \\
\hline E & -0.25 & -0.33 \\
\hline F & +2.00 & +2.15 \\
\hline
\end{tabular}

Table 5. ANOVA for regression analysis

\begin{tabular}{|c|c|c|c|}
\hline Source & DF & MS & $\mathbf{F}$ \\
\hline Regression & $3 \quad 0.00053508$ & 0.00017836 & 5.50 \\
\hline Residual Error & $\begin{array}{ll}23 & 0.00074633\end{array}$ & 0.00003245 & \\
\hline Total & $\begin{array}{ll}26 & 0.00128142\end{array}$ & & \\
\hline
\end{tabular}

\section{CONCLUSION}

The effects of velocity, angle of impact and grit size are experimentally investigated. As the experimental results show, velocity and grit size has a significant effect on the erosion rate and the angle of impact has less significant. An optimum parameter combination for high erosion resistance are the medium velocity $(40 \mathrm{~m} / \mathrm{s})$, minimum angle of impact (30o) and higher grain size $(230 \mu \mathrm{m})$ Similarly maximum velocity $(50 \mathrm{~m} / \mathrm{s})$, maximum angle of impact (90o) and minimum grit size $(120 \mu \mathrm{m})$ yields maximum erosion rate indicating low resistance.

A multiple non-linear regression equation is found for the erosion rate of alumina-zirconia composite. The developed mathematical model based on the Air jet erosion test process facilitate the estimation of erosion rate and proper selection of the parameters for the evaluation of erosion rate characteristics under various factor combinations with a reasonable degree of accuracy.

\section{REFERENCES}

[1] M/s. Saint-Gobain, Ceramic materials and coating solutions, Technical Bulletin \# 290, AluminaZirconia, Grain code 930645.

[2] Shipway P.H., Hutchings I.M.,1996, The role of particle properties in the erosion of brittle materials, Wear 193, pp.105-113.

[3] Hutchings, 1992, TRIBOLOGY: Friction and Wear of Engineering Materials,Edward Arnold, London, pp. 184-185.
[4] Feng Z., Ball A., 1999, The erosion of four materials using seven erodent-towards an understanding, Wear, pp. 233-235, 674-684.

[5] Pawlowski.L,1995, The Science and Engineering of Thermal Spray Coatings, John Wiley and Sons, Chichester,

[6] Wang Jun, Zhang Li, Sun Baode, Zhou Yaohe, 2000 , Study of the $\mathrm{Cr} 3 \mathrm{C} 2-\mathrm{NiCr}$ detonation spray coating, Surface and coating Technology, pp.130 6973.

[7] RajaKumar S., Vijayaraghavan L., Mayuram M M, 2008, Optimization Of Process Parameters For DGun Coating Of Fused Alumina Zirconia Powder Using Taguchi Method, International Conference on Digital Factory, ICDF, pp.1413-1419.

[8] Hutchings I.M., 2000, Solid Particle Wear Testing, vol. 8, ASM International, pp. 343-344.

[9] Rowlands Hefin, Antony Jiju and Knowles Graeme, 2000, An application of experimental design for process optimization. The TQM Magazine Volume 12. Number 2. pp. 78-83

[10] Aminollah Mohammadi, Alireza Fadaei Tehrani, Ehsan Emanian \& Davoud Karimi, 2007, A new approach to surface roughness and roundness improvement in wire electrical discharge turning based on statistical analyses, international journal of manufacturing technology, DOI 10.1007/s 00170007-1179-5

[11] Montgomery DC, 1991, Design and analysis of experiments, 3rd edition Wiley, Singapore

[12] Myers RH, Walpole RE, 1978, Probability and statistics for engineers and scientists, Macmillan, New York.

[13] Zhang Y., Cheng Y.-B., Lathabai S., 2000, Erosion of alumina ceramics by air and water-suspended garnet particles, Wear 240 ,pp. 40-51.

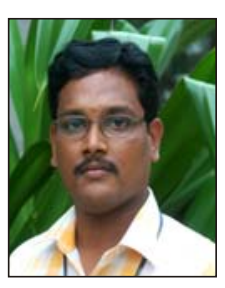

S. Rajakumar is a research scholar in the Department of Mechanical Engineering at Indian Institute of Technology, Madras. He is a graduate in Mechanical Engineering from University of Madras and a postgraduate from Indian Institute of Technology, Madras. 